\title{
Lidar Network Observation of Dust Layer Development over the Gobi Desert in Association with a Cold Frontal System on 22-23 May 2013
}

\author{
Kei KAWAI, Kenji KAI \\ Graduate School of Environmental Studies, Nagoya University, Nagoya, Japan \\ Yoshitaka JIN, Nobuo SUGIMOTO \\ National Institute for Environmental Studies, Tsukuba, Japan \\ and \\ Dashdondog BATDORJ \\ National Agency for Meteorology and Environmental Monitoring, Mongolia \\ (Manuscript received 28 September 2017, in final form 16 January 2018)
}

\begin{abstract}
The Gobi Desert is one of the major sources of Asian dust, which influences the climate system both directly and indirectly through its long-range transport by the westerlies. In this desert, three ground-based lidars are operated in Dalanzadgad, Sainshand, and Zamyn-Uud, Mongolia. This study firstly combined these lidars into a lidar network and shows the spatial development of a dust layer over the desert and the long-range transport of the dust during 22-23 May 2013 via the lidar network. During this dust event, a cold front accompanying an extratropical cyclone moved southeastward across the desert and sequentially passed through Dalanzadgad, Sainshand, and Zamyn-Uud. In Dalanzadgad, in the central part of the desert, a dust storm occurred owing to the strong wind $\left(6-10 \mathrm{~m} \mathrm{~s}^{-1}\right)$ associated with the cold front and reached a top height of $1.6 \mathrm{~km}$. Some of the dust floated at a height of $0.9-1.6 \mathrm{~km}$ along the cold frontal surface. In Sainshand and Zamyn-Uud, in the eastern part of the desert, the dust layer extended from the atmospheric boundary layer (ABL) to the free troposphere in the updraft region of warm air in the cold frontal system. Overall, while the dust layer was moving across the desert with the cold frontal system, it was developing up to the free troposphere. The mechanism of this development can be explained by the combination of two processes as follows: (1) the continuous emission of dust from the desert surface to the ABL by the strong wind around the cold front and (2) the continuous transport of the dust from the ABL to the free troposphere by the updraft of the warm air in the cold frontal system. This mechanism can contribute to the long-range transport of dust by the westerlies in the free troposphere.
\end{abstract}

Keywords Asian dust; cold front; the Gobi Desert; lidar network observation; long-range transport

Corresponding author: Kei Kawai, Graduate School of Environmental Studies, Nagoya University, Furo-cho, Chikusaku, Nagoya 464-8601, Japan

E-mail: kawai.kei@e.mbox.nagoya-u.ac.jp

J-stage Advance Published Date: 26 January 2018

(C) The Author(s) 2018. This is an open access article published by the Meteorological Society of Japan under a Creative Commons Attribution 4.0 International (CC BY 4.0) license (http://creativecommons.org/license/by/4.0). 


\section{Introduction}

Asian dust originates in arid and semi-arid regions of East Asia, such as the Gobi Desert, Taklimakan Desert, and Loess Plateau (Sun et al. 2001; Kurosaki and Mikami 2005; Wu et al. 2016). In the source regions, dust is emitted from the ground surface to the atmospheric boundary layer (ABL) by strong wind. If the dust ascends from the ABL to the free troposphere, it is transported over a long range toward the North Pacific by the middle-latitude westerlies (Kai et al. 1988; Husar et al. 2001; Hara et al. 2009; Uno et al. 2009; Yumimoto et al. 2009). This transported dust influences the climate system both directly and indirectly (Huang et al. 2014). Therefore, the spatial distribution of dust over the source regions is a key factor in the long-range transport of dust.

A ground-based lidar is effective for observing the vertical distribution of dust continuously. In the Taklimakan Desert, a depolarization lidar was installed in 2002 (Tsunematsu et al. 2005; Kai et al. 2008) through the Japan-China Joint Studies on Origin and Transport of Aeolian Dust and its Impact on Climate (ADEC) (e.g., Mikami et al. 2005; Takemi 2005). In the Loess Plateau, a group from Lanzhou University, China, conducts a lidar observation and many other measurements (Huang et al. 2008). In the Gobi Desert, there are two lidars in the eastern part (Sugimoto et al. 2008) and one in the central part (Kawai et al. 2015).

In the Gobi Desert, almost all dust events arise from cold frontal activity (Shao and Wang 2003; Takemi and Seino 2005). A cold front often passes through the desert in spring (Hayasaki et al. 2006). This is related to frequent cyclogenesis in the lee of the AltaiHangayn-Sayan Mountains (Fig. 1) in spring (Chen et al. 1991; Adachi and Kimura 2007; Wang et al. 2009). Therefore, it is important to understand the relationship between dust events and cold fronts. In previous studies, dust events associated with cold fronts were analyzed via satellite images and numerical models (Husar et al. 2001; Adachi et al. 2007; Hara et al. 2009). However, the spatial relationship between dust events and cold fronts, which involves the long-range transport of dust, is not yet shown in detail based on the lidar observations in the source region.

A dust event occurred in the Gobi Desert during the passage of a cold front on 22-23 May 2013. Our previous study showed the dust transport from the ABL to the free troposphere by the cold frontal system during the dust event, based on the lidar in the central part of the desert (Kawai et al. 2015). In the present study,

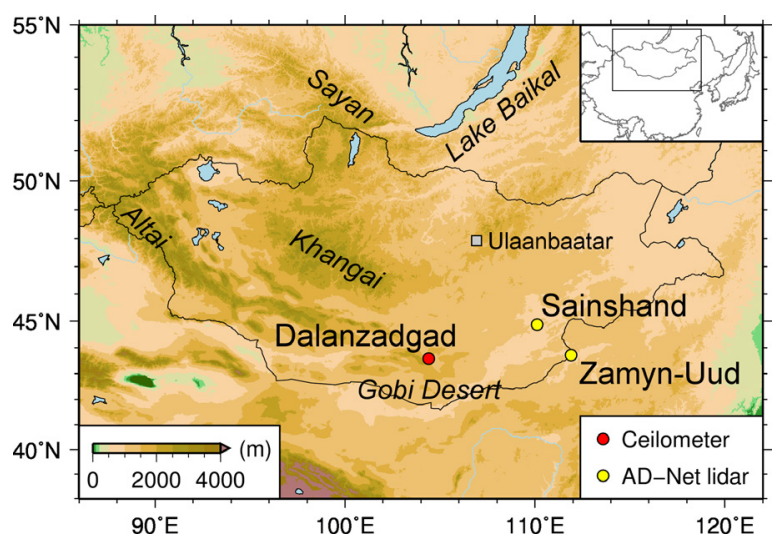

Fig. 1. Topographic map of Mongolia and surrounding areas.

we firstly combined the three lidars in the desert into a lidar network and analyzed the spatial distribution of dust. The purpose of the present study is to show the spatial development of a dust layer and the long-range transport of the dust during the dust event by using the lidar network.

\section{Observations and data}

\subsection{Gobi Desert lidar network}

The lidar network in the Gobi Desert consists of three lidars: one ceilometer in the central part and two AD-Net lidars in the eastern part. A ceilometer is a compact backscatter lidar that is easy to operate and maintain. AD-Net is short for the Asian Dust and Aerosol Lidar Observation Network, which is a widespread lidar network in East Asia (Sugimoto et al. 2008).

\section{a. Ceilometer observation}

The ceilometer is located in Dalanzadgad $\left(43.58^{\circ} \mathrm{N}\right.$, $104.42^{\circ} \mathrm{E}, 1470 \mathrm{~m}$ above sea level (ASL)) in southern Mongolia (Fig. 1). The ceilometer observation has been conducted since the end of April 2013. It is part of the collaborative research between Nagoya University, Japan, and the Information and Research Institute of Meteorology, Hydrology and Environment (IRIMHE), Mongolia. The ceilometer is a Vaisala CL51. The laser wavelength is $910 \mathrm{~nm}$, the pulse repetition rate is $6.5 \mathrm{kHz}$, and the pulse energy is $3.0 \mu \mathrm{J}$. A preliminary ceilometer observation was performed in Tsukuba, Japan, and the observational performance of the ceilometer was verified via a sophisticated lidar (Jin et al. 2015).

The ceilometer outputs a vertical profile of atten- 
uated backscatter coefficients up to a height of 15.4 $\mathrm{km}$ with a height resolution of 10 m every 6 seconds. An attenuated backscatter coefficient is a backscatter coefficient that considers the attenuation of an emitted laser pulse and the backscatter light in the atmosphere. The influence of water vapor on the attenuated backscatter coefficients obtained from the ceilometer is probably small because of low relative humidity in the Gobi Desert, as discussed in Jin et al. (2015). The average of the data for 1 minute was used in this study.

The major scatterers over the Gobi Desert in spring are dust, clouds, and precipitation. Their detection and distinction are based on the magnitude, height, and distribution of attenuated backscatter coefficients. During this dust event, the threshold of attenuated backscatter coefficient for distinguishing dust and the others was about $9 \times 10^{-3} \mathrm{~km}^{-1} \mathrm{sr}^{-1}$. In addition, relative humidity in a region of large attenuated backscatter coefficients supports their distinction. Natsagdorj et al. (2003) showed that relative humidity was low in most dust storms.

\section{b. AD-Net lidar observations}

The AD-Net lidars are located in Sainshand $\left(44.87^{\circ} \mathrm{N}, 110.12^{\circ} \mathrm{E}, 937 \mathrm{~m} \mathrm{ASL}\right)$ and Zamyn-Uud $\left(43.72^{\circ} \mathrm{N}, 111.90^{\circ} \mathrm{E}, 962 \mathrm{~m} \mathrm{ASL}\right)$ in southeastern Mongolia (Fig. 1). These lidars are operated by the National Institute for Environmental Studies (NIES), Japan, and the National Agency for Meteorology and Environmental Monitoring (NAMEM), Mongolia. The lidars are dual-wavelength polarization-sensitive backscatter lidars. The laser wavelengths are 532 and $1064 \mathrm{~nm}$, the pulse repetition rate is $10 \mathrm{~Hz}$, and the pulse energy is $50 \mathrm{~mJ}$. The polarization of backscatter light is measured at a wavelength of $532 \mathrm{~nm}$.

The observational data includes the vertical profiles of attenuated backscatter coefficients at both wavelengths and volume depolarization ratio at a wavelength of $532 \mathrm{~nm}$. The time and height resolutions are 15 minutes and $30 \mathrm{~m}$, respectively. The volume depolarization ratio is an index of particle sphericity. This value is zero for a spherical particle and increases with non-sphericity. We calculated volume color ratio, a relative index of particle size, by dividing the 1064$\mathrm{nm}$ attenuated backscatter coefficient by the $532-\mathrm{nm}$ one. This value increases as particle size increases. The 532-nm attenuated backscatter coefficient near the ground in Zamyn-Uud was calibrated for an incomplete overlap function by using data on 24 May 2013, when the atmosphere was clean following the dust event.

\subsection{Meteorological data}

Surface weather charts produced by the Japan Meteorological Agency (JMA) were used. Surface meteorological observational data were obtained from 3-hourly SYNOP reports acquired from the Integrated Surface Database produced by the National Oceanic and Atmospheric Administration (NOAA), USA (Smith et al. 2011). Three-dimensional gridded meteorological data produced by the National Centers for Environmental Prediction (NCEP) of NOAA were used. The data are NCEP FNL (Final) Operational Global Analysis data of $1^{\circ} \times 1^{\circ}$ grids. This product is generated from the global meteorological data of the Global Data Assimilation System (GDAS) by using the same model as the NCEP global forecast system. In addition, trajectory analyses were performed using the Hybrid Single-Particle Lagrangian Integrated Trajectory (HYSPLIT) model provided by the NOAA Air Resources Laboratory (Stein et al. 2015). The GDAS data of $1^{\circ} \times 1^{\circ}$ grids were selected as the input meteorological data of the trajectory analyses. The local standard time (LST) of Mongolia, which is 8 hours ahead of the coordinated universal time (UTC), is used in this paper.

\section{Results}

\subsection{Meteorological conditions in Mongolia}

Surface weather charts for Mongolia on 22-23 May 2013 are shown in Fig. 2. An extratropical cyclone covered central Mongolia at 14 LST on 22 May (Fig. 2a) and moved northeastward for the next 18 hours. The center pressure of the cyclone was almost constant at $988 \mathrm{hPa}$ during this period. Warm and cold fronts accompanied the cyclone from 20 LST on 22 May (Figs. 2b-d). The cold front extended from the cyclone center to southern Mongolia across the Gobi Desert at 20 LST on 22 May (Fig. 2b) and then moved southeastward through the desert at a speed of about $30 \mathrm{~km} \mathrm{~h}^{-1}$. During the movement, it passed through Dalanzadgad between 14 and 20 LST on 22 May, Sainshand between 20 LST on 22 May and 02 LST on 23 May, and Zamyn-Uud between 02 and 08 LST on 23 May.

Figure 3 shows the meteorological fields observed around Mongolia at the same time as the second and third weather charts (Figs. 2b, c) obtained from the SYNOP report. At 20 LST on 22 May, the cold air behind the cold front covered central Mongolia (including Dalanzadgad), and the warm air in front of the cold front covered eastern Mongolia (Fig. 3a). At 02 LST on 23 May, the cold air expanded to eastern Mongolia (including Sainshand) while the cold front 
(a) 14 LST 22 May



(c) 02 LST 23 May

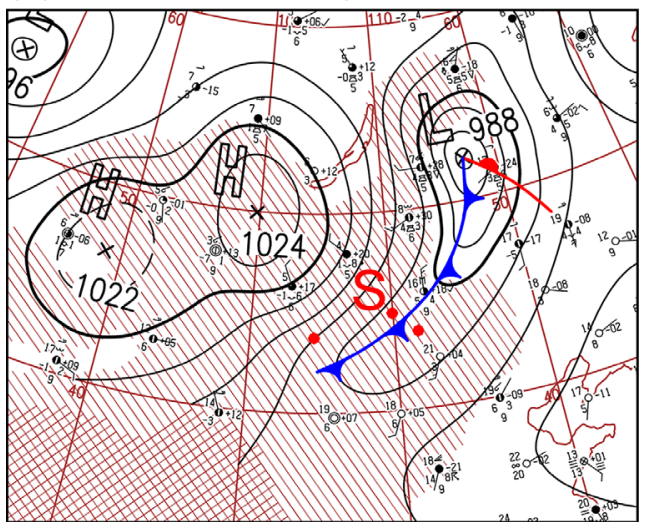

(b) 20 LST 22 May

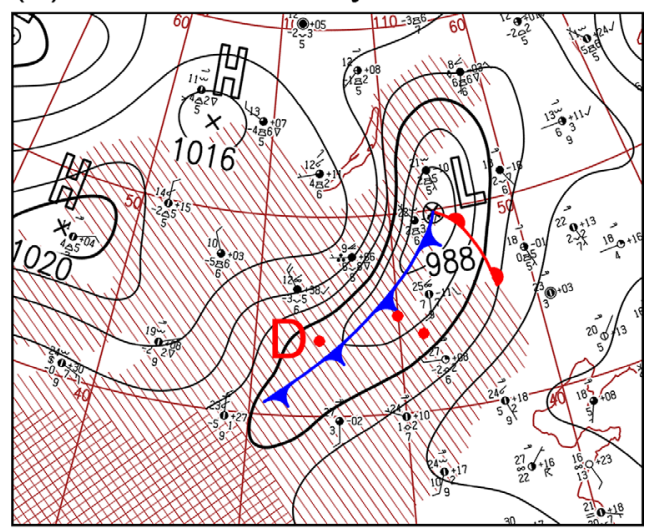

(d) 08 LST 23 May

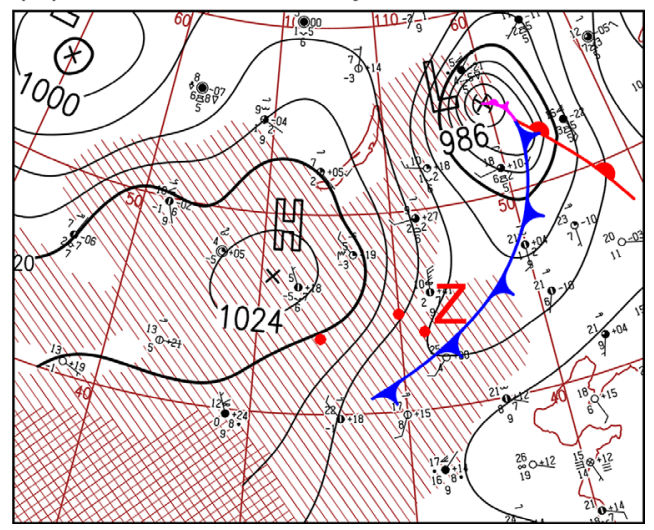

Fig. 2. Surface weather charts for Mongolia at (a) 14 LST and (b) 20 LST on 22 May and at (c) 02 LST and (d) 08 LST on 23 May 2013 provided by JMA. The red dots show the locations of Dalanzadgad (D), Sainshand (S), and Zamyn-Uud (Z). The sparse and dense red-shaded areas indicate altitudes of more than 1500 and $3000 \mathrm{~m}$ above sea level, respectively.

(a) 20 LST 22 May

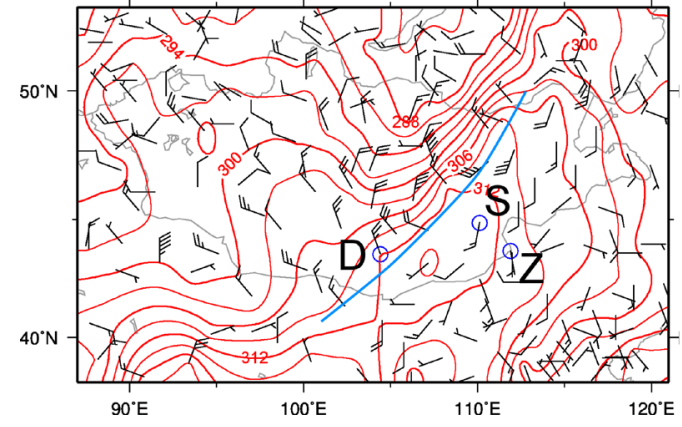

(b) 02 LST 23 May

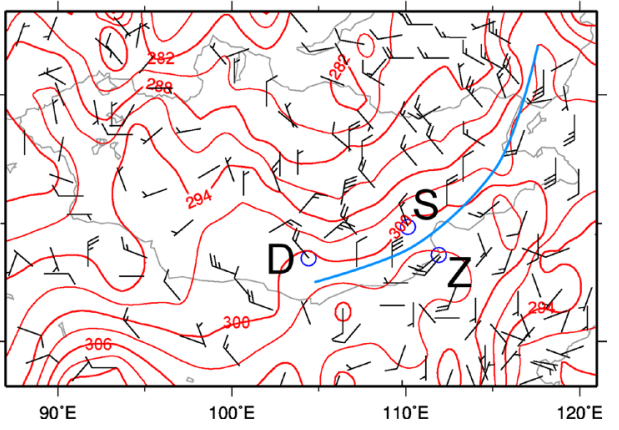

Fig. 3. Potential temperature (red contours; every $3 \mathrm{~K}$ ) and wind (barbs) observed at (a) 20 LST on 22 May and (b) 02 LST on 23 May 2013 obtained from the SYNOP report. The half and full barbs represent the wind speeds of 2 and $4 \mathrm{~m} \mathrm{~s}^{-1}$, respectively. The blue lines indicate the cold fronts transcribed from the weather charts (Figs. $2 \mathrm{~b}, \mathrm{c})$. The blue circles with the letters $\mathrm{D}, \mathrm{S}$, and Z show the locations of Dalanzadgad, Sainshand, and ZamynUud, respectively. 
(a) 20 LST 22 May

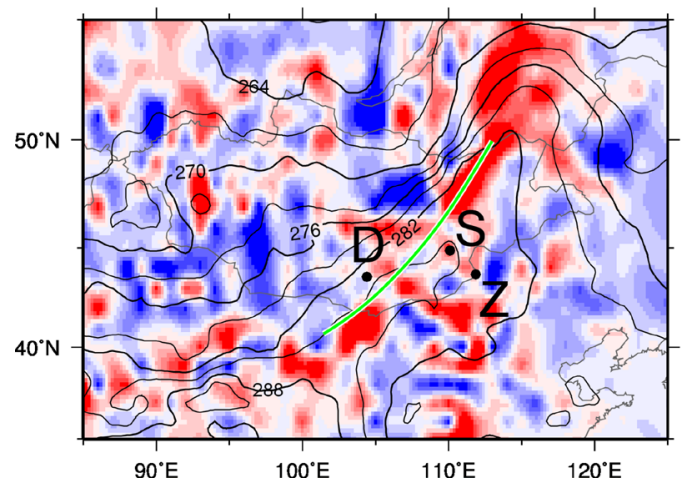

(b) 02 LST 23 May

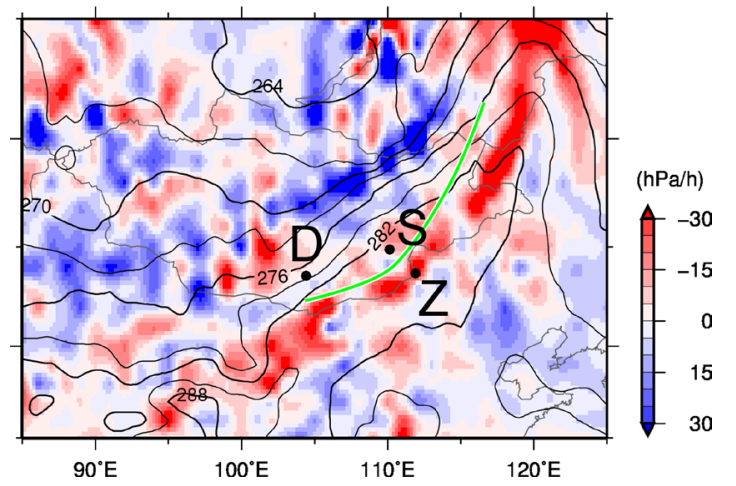

Fig. 4. Temperature (contours; every $3 \mathrm{~K}$ ) and vertical velocity (color) at $700 \mathrm{hPa}$ at (a) $20 \mathrm{LST}$ on $22 \mathrm{May}$ and (b) 02 LST on 23 May 2013 obtained from the NCEP FNL data. For the vertical velocity, a negative value (red) indicates an updraft, whereas a positive value (blue) indicates a downdraft. The green lines indicate the surface cold fronts transcribed from the weather charts (Figs. 2b, c). The black dots with D, S, and $\mathrm{Z}$ show the locations of Dalanzadgad, Sainshand, and Zamyn-Uud, respectively.

moved southeastward (Fig. 3b). At both these times, the wind directions were between north and northwest in the cold air and between south and west in the warm air. These wind conditions show cold and warm air advections. The cold and warm airflows converged along the cold front.

Figure 4 presents meteorological fields at $700 \mathrm{hPa}$ at the same times as in Fig. 3 obtained from the NCEP FNL data. The height at $700 \mathrm{hPa}$ is about $1.5-2.0 \mathrm{~km}$ above the ground in Mongolia. At both times in Fig. 4 , updrafts spread the warm air in along the surface cold front. These updrafts were caused by the convergence of the cold and warm air on the ground (Fig. $3)$. Therefore, the warm air on the ground ascended onto the cold air, as shown in the general cold frontal system (e.g., Simpson 1997; Wallace and Hobbs 2006).

\subsection{Results in Dalanzadgad, located in the central part of the desert}

Figure 5 indicates the temporal variations in surface meteorological elements observed in Dalanzadgad from 12 LST on 22 May to 09 LST on 23 May 2013. Figure 6 shows the time-height cross sections of a ceilometer observation result and meteorological conditions obtained from the NCEP FNL data in Dalanzadgad during the same period as in Fig. 5. In Fig. 6, four characteristic regions were discerned and are indicated by the letters A-D. They are discussed as follows.

Region A of medium to large attenuated backscatter

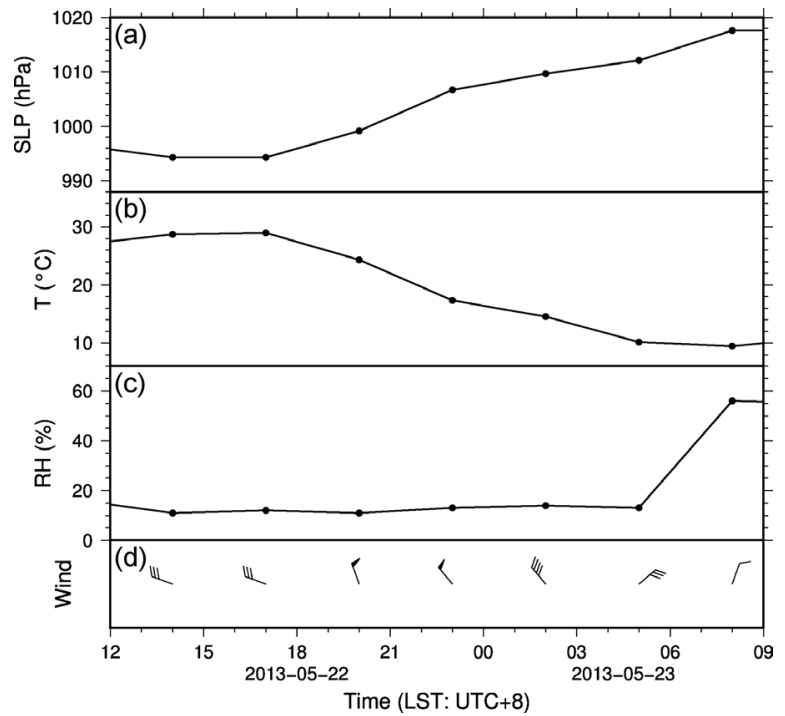

Fig. 5. Time series of the (a) sea level pressure (SLP), (b) temperature (T), (c) relative humidity $(\mathrm{RH})$, and (d) wind observed in Dalanzadgad from 12 LST on 22 May to 09 LST on 23 May 2013 (after Kawai et al. 2015). The half and full barbs and the pennants represent the wind speeds of 1,2 , and $10 \mathrm{~m} \mathrm{~s}^{-1}$, respectively.

coefficients $\left(>1.0 \times 10^{-3} \mathrm{~km}^{-1} \mathrm{sr}^{-1}\right.$, light blue to red) shows a dust storm between the ground and a height of $1.6 \mathrm{~km}$ from 14 LST on 22 May to 02 LST on 23 May (Fig. 6a). Near the ground during the dust storm, 


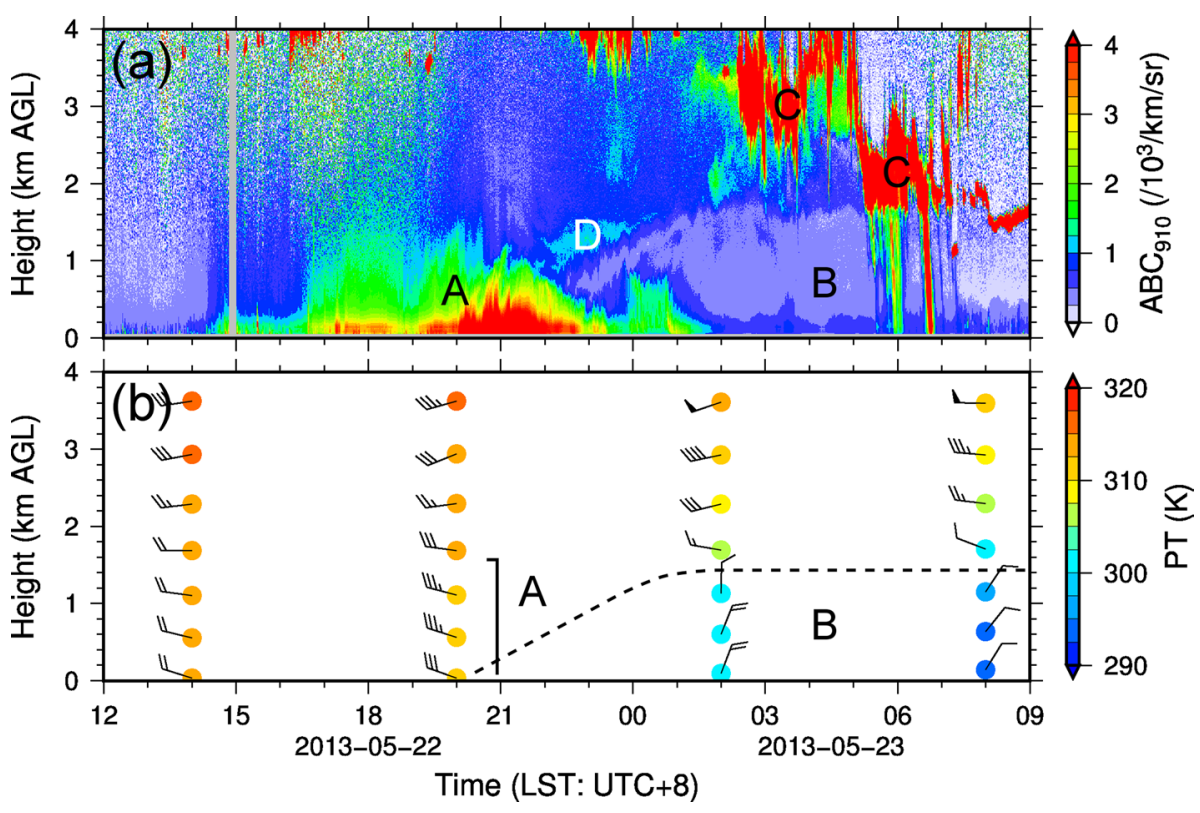

Fig. 6. Time-height cross sections of the (a) 910-nm attenuated backscatter coefficient (ABC) observed by the ceilometer (after Kawai et al. 2015) and (b) potential temperature (PT) and horizontal wind obtained from the NCEP FNL data for Dalanzadgad during the same period as in Fig. 5. The half and full barbs and pennants represent the wind speeds of 2, 4, and $20 \mathrm{~m} \mathrm{~s}^{-1}$, respectively. Regions A-D correspond to a dust storm, cold air, clouds, and a dust layer, respectively. The dotted line represents the top of the cold air.

the relative humidity was $11-14 \%$ (Fig. $5 \mathrm{c}$ ), and the wind speed was $6-10 \mathrm{~m} \mathrm{~s}^{-1}$ (Fig. 5d). Thus, the strong wind raised the dust from the desert surface. In the dust storm at 20 LST on 22 May, the potential temperature was constant at $312 \mathrm{~K}$ with height, and the wind speed was $12-14 \mathrm{~m} \mathrm{~s}^{-1}$ (region A in Fig. 6b). The atmospheric neutral stability and the strong wind show that vertical and horizontal mixing was active because of turbulence in the dust storm.

The sea level pressure increased by $23.3 \mathrm{hPa}$ from 17 LST on 22 May to 08 LST on 23 May (Fig. 5a). The temperature decreased from $28.9^{\circ} \mathrm{C}$ at $17 \mathrm{LST}$ on 22 May to $9.4^{\circ} \mathrm{C}$ at 08 LST on 23 May (Fig. 5b). Hence, the cold front (Fig. 2) passed between 17 and 20 LST on 22 May, and the cold air (Fig. 3) started to advect on the ground during the dust storm.

Judging from the potential temperature and wind conditions, the vertical structure of the cold air is shown by region B under the dotted line in Fig. 6 b. The sloping top height between 20 LST on 22 May and 01 LST on 23 May was the cold frontal surface. The top height of the cold air is assumed to be about $1.4 \mathrm{~km}$ at 02 and 08 LST on 23 May. In particular, the top height at 08 LST corresponds to the cloud base height observed by the ceilometer (Fig. 6a).
The potential temperature was $301 \mathrm{~K}$ at $02 \mathrm{LST}$ and 294-298 K at 08 LST on 23 May (Fig. 6b). The wind directions in and above the cold air were northeast and west, respectively. Most of the cold air indicates small attenuated backscatter coefficients $\left(<0.5 \times 10^{-3}\right.$ $\mathrm{km}^{-1} \mathrm{sr}^{-1}$, light purple) from 2230 LST on 22 May (Fig. 6a), where little dust was floating. The leading edge of the cold air was occupied by the dust storm.

Region $\mathrm{C}$ of medium to large attenuated backscatter coefficients $\left(>1.0 \times 10^{-3} \mathrm{~km}^{-1} \mathrm{sr}^{-1}\right.$, red) shows clouds over a height of $1.6 \mathrm{~km}$ between 02 and 07 LST on 23 May (Fig. 6a). It is likely that the clouds were generated by the updraft of the warm air (Fig. 4), as a general cold frontal system (e.g., Simpson 1997; Wallace and Hobbs 2006). Precipitation is shown by the region of middle to large attenuated backscatter coefficients $\left(>1.0 \times 10^{-3} \mathrm{~km}^{-1} \mathrm{sr}^{-1}\right.$, light blue to red) under the clouds between 05 and 07 LST on 23 May. The precipitation led to the increase in relative humidity at 08 LST on 23 May (Fig. 5c).

Region $\mathrm{D}$, which is indicated by medium attenuated backscatter coefficients $\left(1.0-1.4 \times 10^{-3} \mathrm{~km}^{-1} \mathrm{sr}^{-1}\right.$, light blue) at a height of $0.9-1.6 \mathrm{~km}$ between 22 LST on 22 May and 00 LST on 23 May, shows a dust layer (Fig. 6a). The thickness of the dust layer ranged from 
0.2 to $0.5 \mathrm{~km}$. Because it was located over the cold frontal surface, the dust was probably transported from the dust storm by the updraft of the warm air (Fig. 4). The subsequent movement of the dust layer will be discussed in Section 4 by using trajectory analysis.

\subsection{Results in Sainshand, located in the eastern part of the desert}

Figure 7 presents the temporal fluctuations in surface meteorological elements observed in Sainshand in the eastern part of the Gobi Desert from 18 LST on 22 May to 15 LST on 23 May 2013. Figures 8 and 9 show the time-height cross sections of lidar observation results and meteorological conditions obtained from the NCEP FNL data, respectively, for Sainshand during the same period as in Fig. 7.

Between 22 LST on 22 May and 01 LST on 23 May, a dust storm is shown by region $\mathrm{E}$ of large attenuated backscatter coefficients $\left(>5.5 \times 10^{-3} \mathrm{~km}^{-1} \mathrm{sr}^{-1}\right.$, yellow to red) on the ground (Fig. 8a). At 23 LST on 22 May, during the dust storm, the wind speed was 11

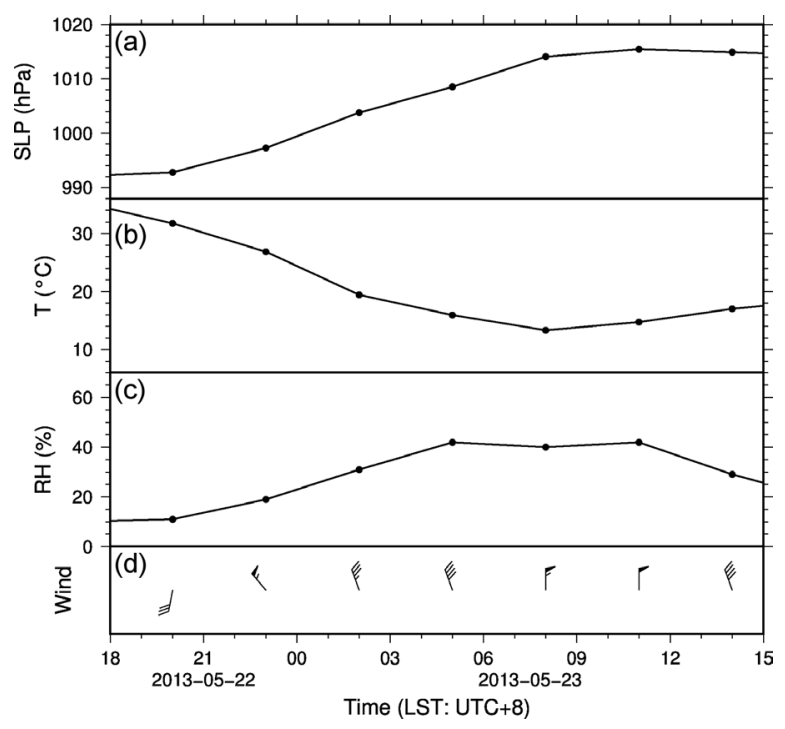

Fig. 7. Same as Fig. 5, except that the location is Sainshand, and the period is from 18 LST on 22 May to 15 LST on 23 May 2013.
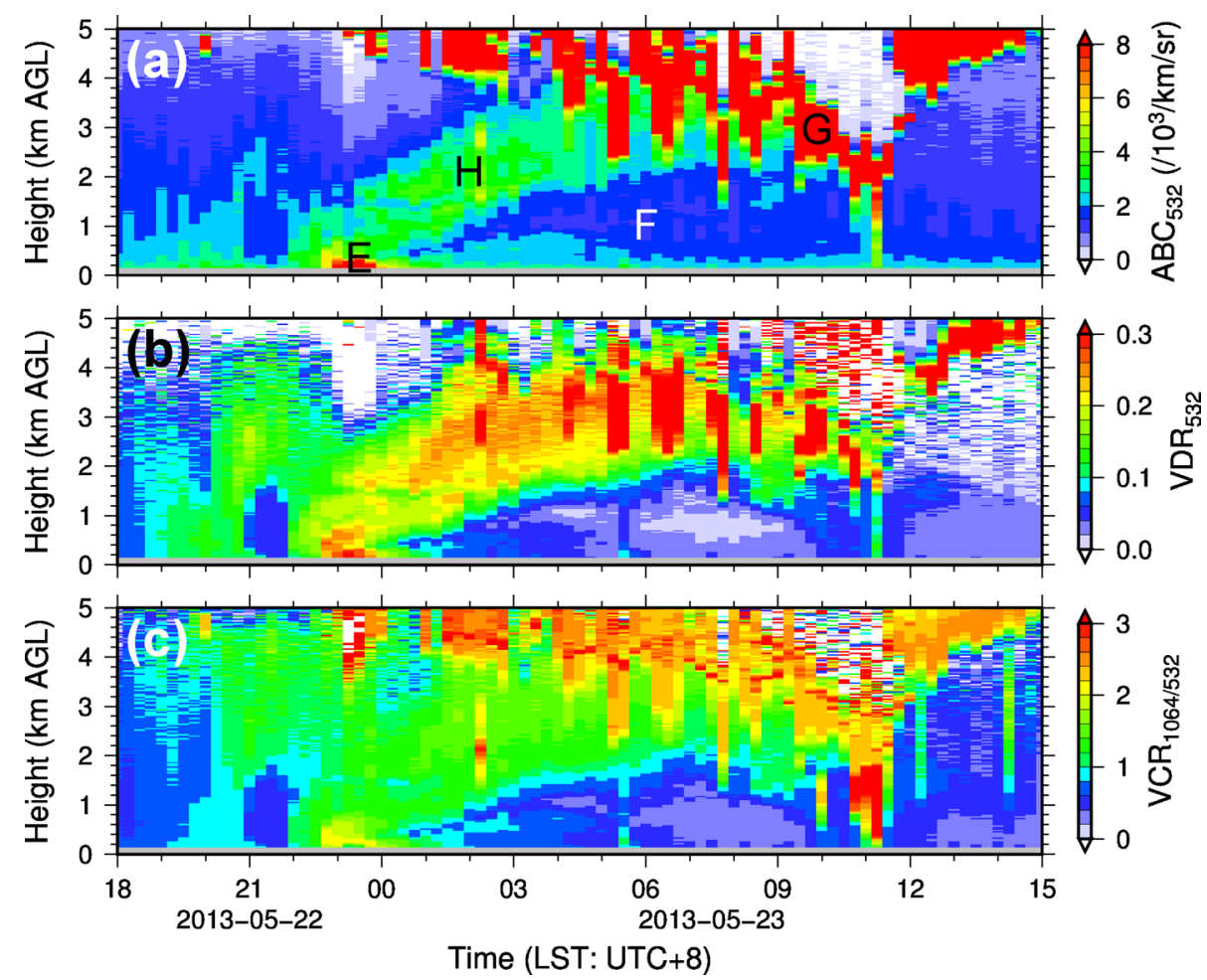

Fig. 8. Time-height cross sections of the (a) 532-nm attenuated backscatter coefficient (ABC), (b) 532-nm volume depolarization ratio (VDR), and (c) 1064/532-nm volume color ratio (VCR) at a height of 0-5 km observed by the AD-Net lidar in Sainshand during the same period as in Fig. 7. Regions E-H correspond to a dust storm, cold air, clouds, and a dust layer, respectively. 


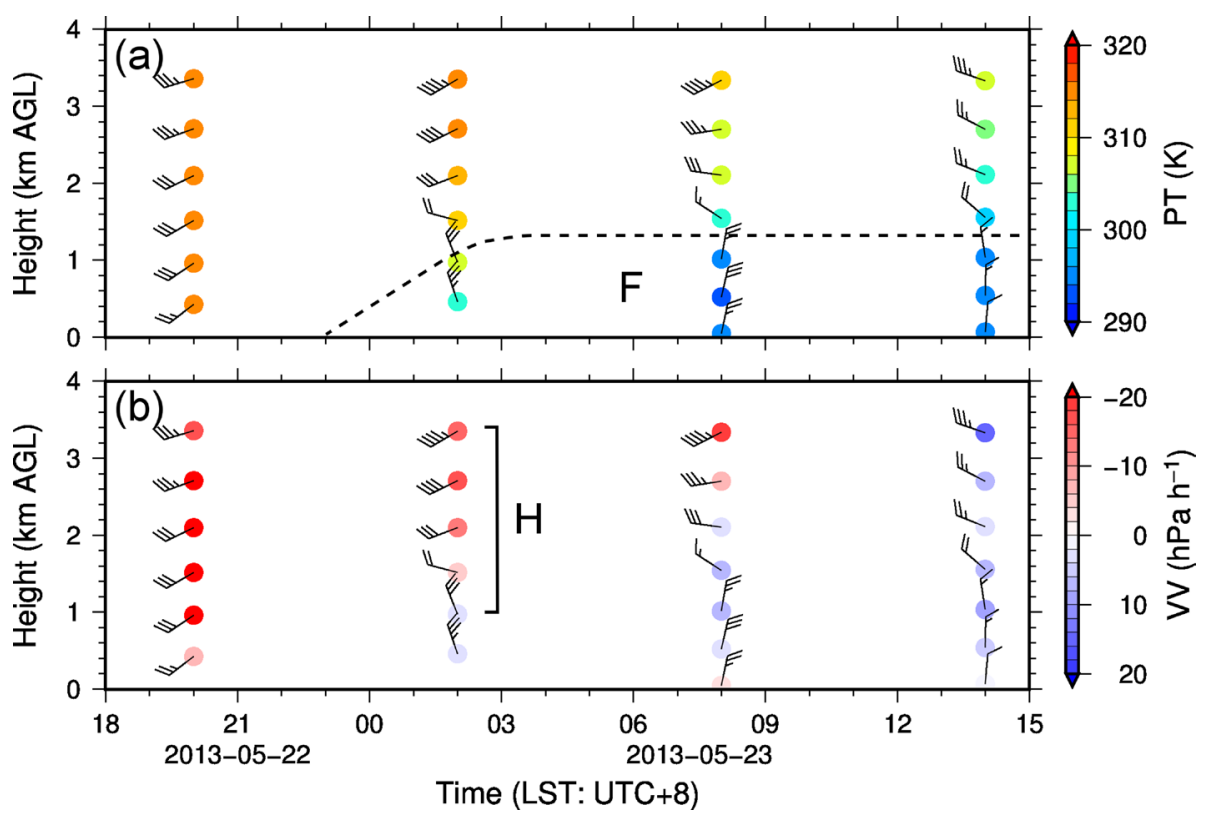

Fig. 9. Time-height cross sections of the (a) potential temperature (PT) and horizontal wind and (b) vertical velocity (VV) and horizontal wind obtained from the NCEP FNL data for Sainshand during the same period as in Figs. 7 and 8. The half and full barbs and pennants represent the wind speeds of 2, 4, and $20 \mathrm{~m} \mathrm{~s}^{-1}$, respectively. Regions $\mathrm{F}$ and $\mathrm{H}$ are the same as in Fig. 8.

$\mathrm{m} \mathrm{s}^{-1}$ (Fig. 7d), and the relative humidity was $19 \%$ (Fig. 7c). In the dust storm, the volume depolarization ratio was $0.2-0.3$ (Fig. 8 b), and the volume color ratio was about 2.0 (Fig. 8c).

The sea level pressure increased by $21.3 \mathrm{hPa}$ from 20 LST on 22 May to 08 LST on 23 May (Fig. 7a). The temperature dropped from $35.4^{\circ} \mathrm{C}$ at $17 \mathrm{LST}$ on 22 May to $13.3^{\circ} \mathrm{C}$ at $08 \mathrm{LST}$ on 23 May (Fig. 7b). Between 20 and 23 LST on 22 May, the wind direction changed from south to northwest, and the wind speed increased from 6 to $11 \mathrm{~m} \mathrm{~s}^{-1}$ (Fig. 7d). According to these features, the cold front shown in Fig. 2 passed through between 20 and 23 LST on 22 May, and the cold air replaced the warm air, as shown in Fig. 3.

Judging from the potential temperature and wind conditions, the vertical structure of the cold air is indicated in region $\mathrm{F}$ below the dotted line in Fig. 9a. The top height was $1.1 \mathrm{~km}$ at 02 LST and $1.3 \mathrm{~km}$ at 08 and 14 LST on 23 May. The potential temperature was $303-307 \mathrm{~K}$ at $02 \mathrm{LST}$ and $295 \mathrm{~K}$ at 08 and $14 \mathrm{LST}$ on 23 May. At 08 and 14 LST on 23 May, there was an inversion layer between 1.1 and $1.5 \mathrm{~km}$ in height. The wind directions in and above the cold air were north and west, respectively. The attenuated backscatter coefficients were small $\left(<2.0 \times 10^{-3} \mathrm{~km}^{-1} \mathrm{sr}^{-1}\right.$, blue $)$ in the cold air after the dust storm (region F in Fig. 8a), indicating little floating dust.

Region $\mathrm{G}$ of medium to large attenuated backscatter coefficients $\left(>2.0 \times 10^{-3} \mathrm{~km}^{-1} \mathrm{sr}^{-1}\right.$, red) shows clouds, which were located around a height of $2-5 \mathrm{~km}$ (Fig. 8a). Most of the clouds indicate volume depolarization ratios of more than 0.2 (Fig. 8b), indicating the presence of ice crystals (Shimizu et al. 2004). The temperatures around the clouds were between 0 and $-10^{\circ} \mathrm{C}$ according to the NCEP FNL data (not shown). Therefore, it is likely that the dust particles mentioned later worked as ice nuclei, as suggested by Sakai et al. (2003). The volume color ratio in the clouds was 2.0-2.4 (Fig. 8c). The region of medium attenuated backscatter coefficients $\left(2.0-6.0 \times 10^{-3} \mathrm{~km}^{-1} \mathrm{sr}^{-1}\right.$, light blue to yellow) under the clouds around 11 LST on 23 May shows precipitation (Fig. 8a). In the precipitation, the volume depolarization ratio was about 0.1 (Fig. $8 \mathrm{~b})$, which is consistent with that reported by Sassen (2006). The volume color ratio of the precipitation was 2.0-3.0 (Fig. 8c).

A dust layer is shown by the medium attenuated backscatter coefficients $\left(2.0-6.0 \times 10^{-3} \mathrm{~km}^{-1} \mathrm{sr}^{-1}\right.$, light blue to yellow) in region $\mathrm{H}$ (Fig. 8a). It extended from the dust storm (region E) to the clouds (region G) over 
the cold air (region F). It seems that the dust layer was mixed with the clouds. The top height of the dust layer increased from $1.6 \mathrm{~km}$ at $22 \mathrm{LST}$ on 22 May to at least $4.0 \mathrm{~km}$ at $04 \mathrm{LST}$ on 23 May. The presence of the dust layer above a height of $4.0 \mathrm{~km}$ was unclear because of the clouds. The thickness of the dust layer was between 1.6 and $2.5 \mathrm{~km}$. In the dust layer, the volume depolarization ratio was $0.1-0.3$ (Fig. 8b), and the volume color ratio was 1.0-2.0 (Fig. 8c). According to the volume color ratio, the dust particles were smaller than the precipitation particles and the ice crystals of the clouds. Vertical velocity represents updraft in the dust layer at 02 LST on 23 May (region $\mathrm{H}$ in Fig. 9b). Therefore, the dust layer was distributed in the updraft region of the warm air in the cold frontal system.

\subsection{Results in Zamyn-Uud, located in the eastern part of the desert}

The time series of surface meteorological elements observed in Zamyn-Uud on 22-23 May 2013 are indicated in Fig. 10. Figures 11 and 12 show the timeheight cross sections of the lidar observation results and meteorological conditions obtained from the NCEP FNL data, respectively, for Zamyn-Uud during the same period as in Fig. 10. Three characteristic regions were found and are denoted with the letters $\mathrm{I}-\mathrm{K}$. As with Sainshand, a dust layer (region I) was located over the cold air (region J) and probably mixed with a cloud (region K).

The dust layer over the cold air is shown by medium attenuated backscatter coefficients $\left(1.6-4.0 \times 10^{-3}\right.$ $\mathrm{km}^{-1} \mathrm{sr}^{-1}$, light blue to green) up to a height of about 4 $\mathrm{km}$ until 17 LST on 23 May (region I in Fig. 11a). The top height increased from $1.4 \mathrm{~km}$ at 03 LST to $3.8 \mathrm{~km}$ at 15 LST on 23 May. The thickness ranged from 0.3 to $1.7 \mathrm{~km}$. In the dust layer, the volume depolarization ratio was $0.2-0.3$ (Fig. 11b), and the volume color ratio was 1.0-2.4 (Fig. 11c). As with Sainshand, the dust layer was located in the updraft region (region I in Fig. 12b).

The sea level pressure increased by $13.4 \mathrm{hPa}$ from 17 LST on 22 May to 11 LST on 23 May (Fig. 10a). The temperature decreased from $32.5^{\circ} \mathrm{C}$ at $17 \mathrm{LST}$ on 22 May to $18.4^{\circ} \mathrm{C}$ at 05 LST on 23 May (Fig. 10b). The wind direction changed from southwest to northwest between 02 and 05 LST on 23 May (Fig. 10d). These characteristics show that the cold front (Fig. 2) passed through between 02 and 05 LST on 23 May, and the cold air replaced the warm air (Fig. 3).

Judging from the potential temperature and wind conditions, the cold air is indicated by region $\mathrm{J}$ below

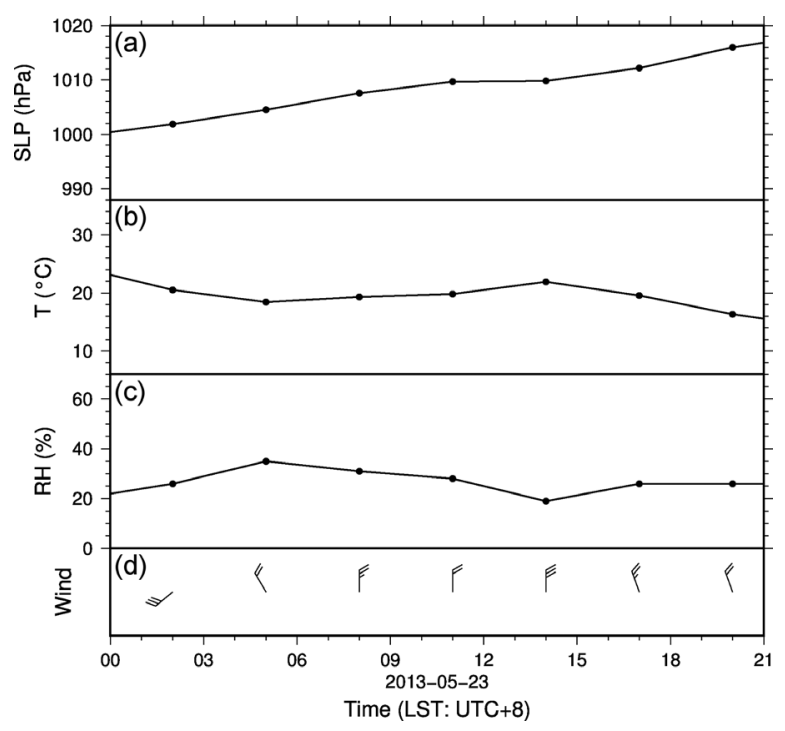

Fig. 10. Same as Fig. 5, except that the location is Zamyn-Uud, and the period is from 00 to 21 LST on 23 May 2013.

the dotted line in Fig. 12a. The top height of the cold air was about $1.0 \mathrm{~km}$ at 08 LST and $1.3 \mathrm{~km}$ at 14 and 20 LST on 23 May. The potential temperature in the cold air was $297-306 \mathrm{~K}$. The wind directions rotated from north in the cold air to west above the cold air. This counterclockwise rotation is consistent with the cold air advection. The attenuated backscatter coefficients were small $\left(<1.6 \times 10^{-3} \mathrm{~km}^{-1} \mathrm{sr}^{-1}\right.$, blue $)$ in the upper part of the cold air (region J in Fig. 11a).

Region $\mathrm{K}$, which is indicated by medium to large attenuated backscatter coefficients $\left(>1.6 \times 10^{-3}\right.$ $\mathrm{km}^{-1} \mathrm{sr}^{-1}$, red) over a height of $2.2 \mathrm{~km}$ between 1700 and 1930 LST on 23 May, shows a cloud (Fig. 11a). It seems that the cloud was mixed with the dust layer. In the cloud, the volume depolarization ratio was mostly greater than 0.3 (Fig. 11b), and the volume color ratio was more than 3.0 (Fig. 11c). As with Sainshand, it is likely that the dust particles worked as ice nuclei. The ice crystals of the cloud were larger than the dust particles according to their color ratios.

\section{Discussion}

\subsection{Dust layer development}

Figure 13 illustrates the observational models at the lidar observation sites during the dust event. The characteristics of the dust layers over the cold air are summarized in Table 1. In Dalanzadgad, a dust storm occurred around the cold front and reached a top 

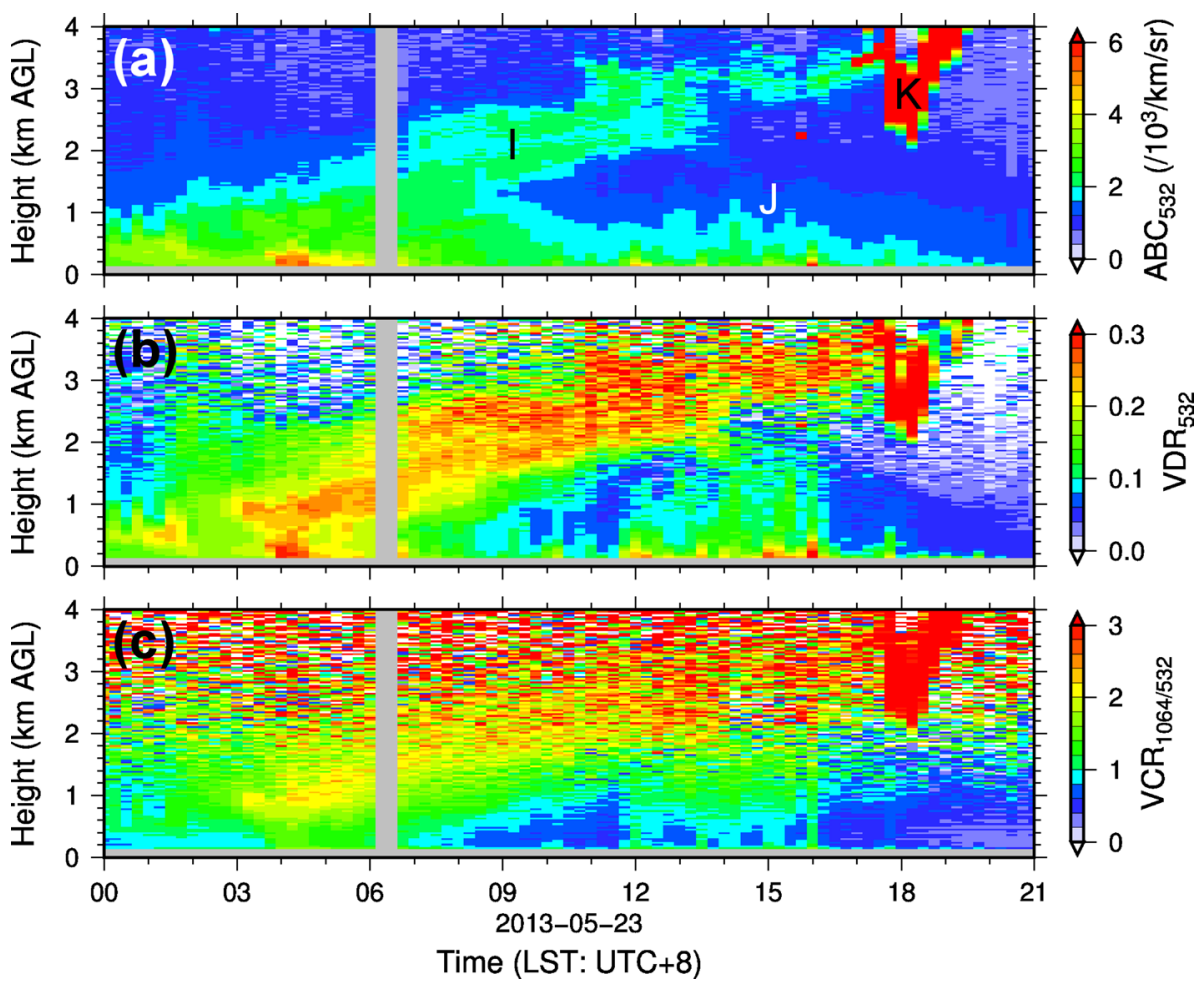

Fig. 11. Same as Fig. 8, except that the location is Zamyn-Uud, the height range is $0-4 \mathrm{~km}$, and the period is from 00 to 21 LST on 23 May 2013 (same as in Fig. 10). Regions I-K correspond to a dust layer, cold air, and a cloud, respectively.

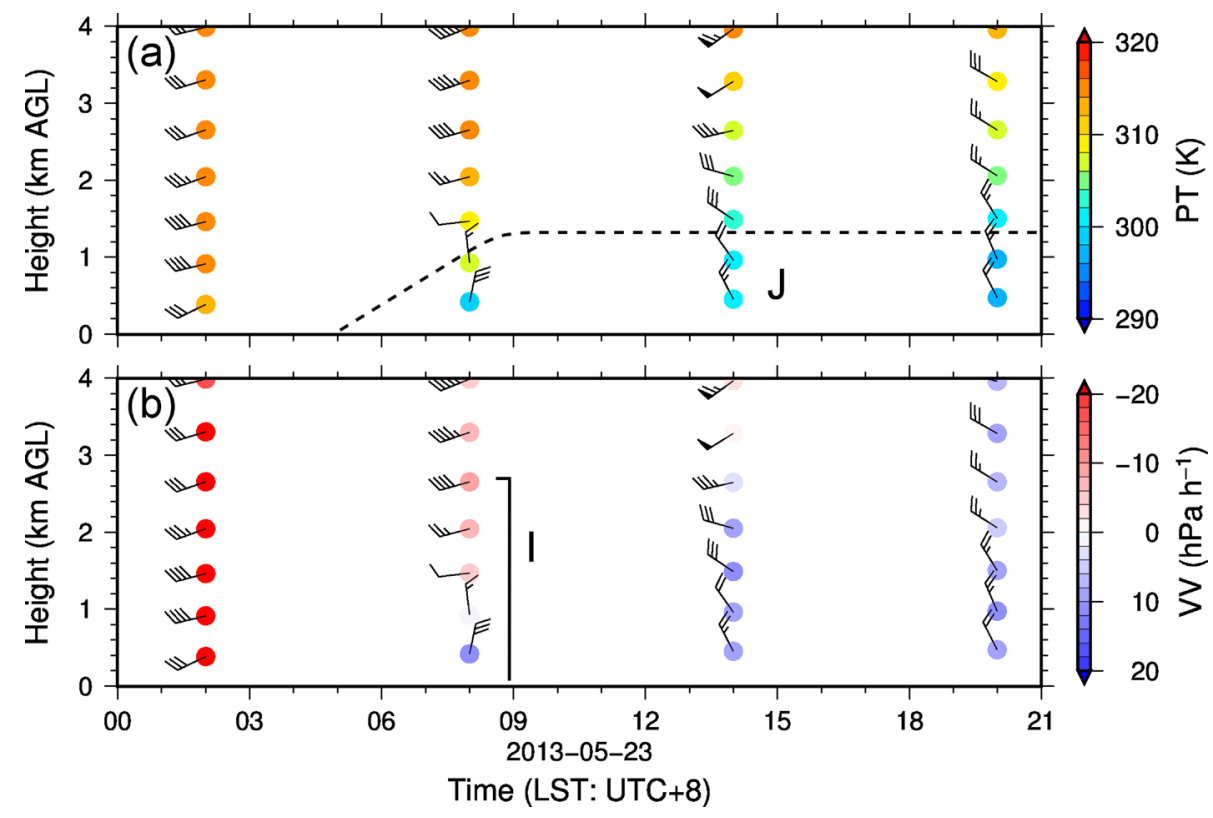

Fig. 12. Same as Fig. 9, except that the location is Zamyn-Uud, and the period is from 00 to 21 LST on 23 May 2013 (same as Fig. 10). Regions I and J are the same as in Fig. 11. 


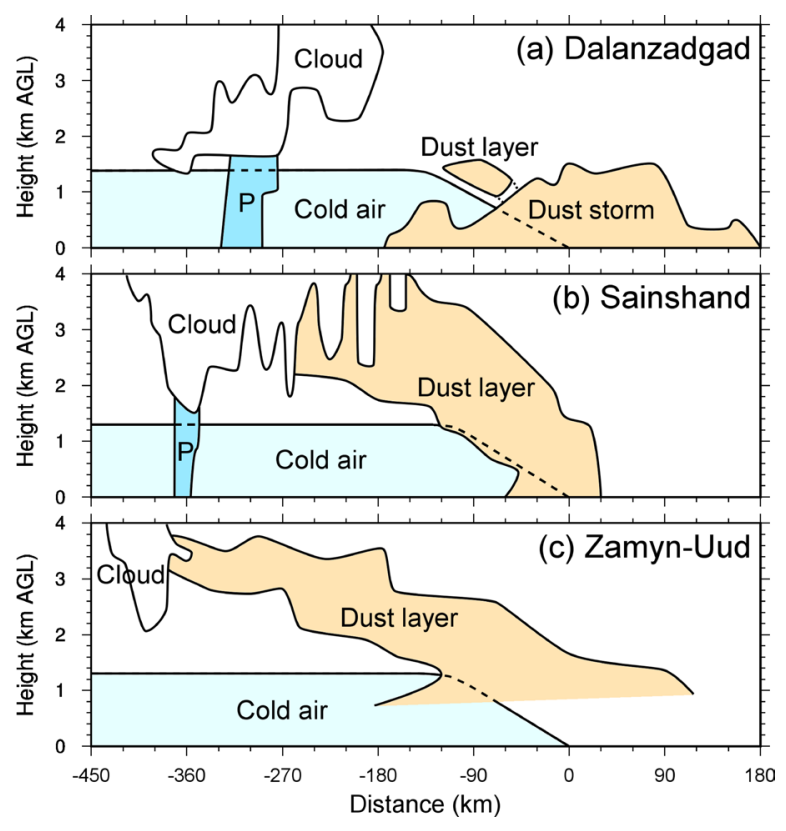

Fig. 13. Observational models for (a) Dalanzadgad, (b) Sainshand, and (c) Zamyn-Uud at a height of $0-4 \mathrm{~km}$ during the dust event. The distance was calculated by using the moving speed of the cold front $\left(30 \mathrm{~km} \mathrm{~h}^{-1}\right)$. The distance of $0 \mathrm{~km}$ indicates the leading edge of the cold air (i.e., the cold front on the ground) at each observation site. The right side is the moving direction of the cold front (southeast). The letter $\mathrm{P}$ means precipitation.

Table 1. Summary of the maximum top height and thickness range of the dust layer over cold air observed in each site on 22-23 May 2013. In Sainshand, the presence of the dust layer above a height of $4.0 \mathrm{~km}$ was unclear because of clouds.

\begin{tabular}{cccc}
\hline Dust layer & Dalanzadgad & Sainshand & Zamyn-Uud \\
\hline $\begin{array}{c}\text { Maximum } \\
\text { top height }\end{array}$ & $1.6 \mathrm{~km}$ & $(4.0 \mathrm{~km})$ & $3.8 \mathrm{~km}$ \\
$\begin{array}{l}\text { Minimum } \\
\text { thickness }\end{array}$ & $0.2 \mathrm{~km}$ & $1.6 \mathrm{~km}$ & $0.3 \mathrm{~km}$ \\
$\begin{array}{c}\text { Maximum } \\
\text { thickness }\end{array}$ & $0.5 \mathrm{~km}$ & $2.5 \mathrm{~km}$ & $1.7 \mathrm{~km}$ \\
\hline
\end{tabular}

height of $1.6 \mathrm{~km}$ (Fig. 13a). A dust layer was distributed at a height of $0.9-1.6 \mathrm{~km}$ over the cold air, with a thickness that ranged from 0.2 to $0.5 \mathrm{~km}$. Forward trajectories for the dust layer are presented in Fig. 14. The trajectories extended eastward, reached the east-

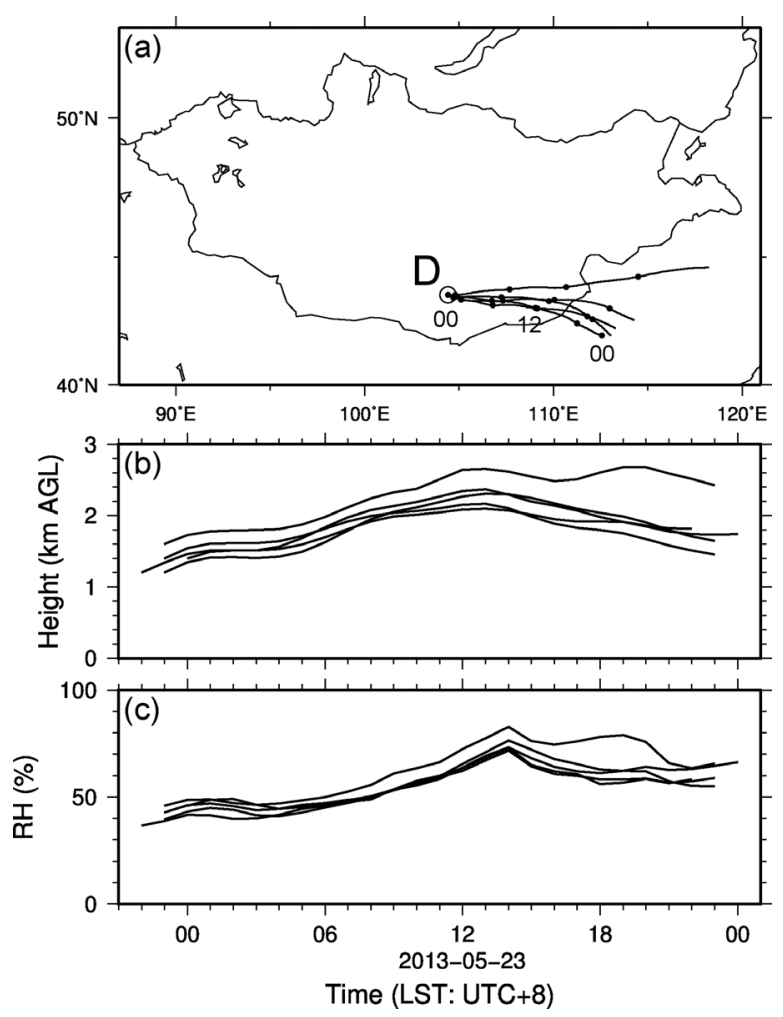

Fig. 14. (a) The locations, (b) the height above ground level (AGL), and (c) the relative humidity (RH) of 24-hour forward trajectories of air parcels corresponding to the dust layer that was observed over cold air in Dalanzadgad on 22-23 May 2013. In panel (a), the dots on the trajectories indicate their location every 6 hours, and the numerical values of 00 and 12 near the trajectories represent the hours of 00 and 12 LST, respectively.

ern part of the Gobi Desert (Fig. 14a), and ascended to a height of more than $2.0 \mathrm{~km}$ for the first $13-15$ hours (Fig. 14b). The relative humidity along the trajectories was about $50 \%$ until 08 LST on 23 May (Fig. 14c). By contrast, the dust layers observed in Sainshand and Zamyn-Uud reached a height of about $4 \mathrm{~km}$ (Figs. $13 \mathrm{~b}, \mathrm{c})$ and were $1.6-2.5$ and $0.3-1.7 \mathrm{~km}$ thick, respectively. Therefore, the dust layer produced during this dust event was developing upward from the $\mathrm{ABL}$ to the free troposphere while moving eastward through the Gobi Desert with the cold frontal system.

It is suggested that the development of the dust layer was based on the combination of the following two processes: (1) the continuous emission of dust from the desert surface to the ABL and (2) the contin- 


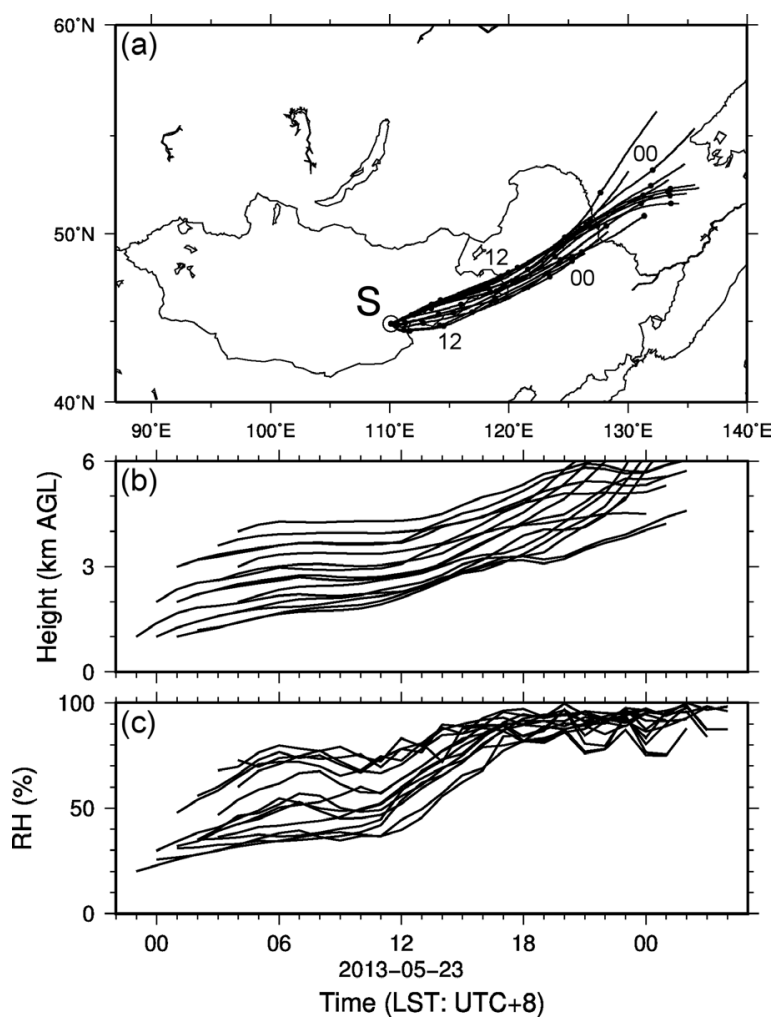

Fig. 15. Same as Fig. 14, except that the location is Sainshand.

uous transport of the dust from the ABL up to the free troposphere.

Process (1): Dust was raised from the ground to the $\mathrm{ABL}$ over the Gobi Desert by the strong wind around the cold front. It is likely that the dust layer was supplied continuously with new dust from the desert surface while moving through the desert.

Process (2): The dust in the ABL was transported to the free troposphere by the updraft of the warm air in the cold frontal system, as suggested by Kawai et al. (2015). The updraft is shown in Figs. 9b, 12b, and $14 \mathrm{~b}$. This transport must have continued while the dust layer was moving through the desert with the cold frontal system.

In conclusion, the cold frontal system induced the dust layer development from the ABL up to the free troposphere by the combination of the two processes. This mechanism should have contributed to the longrange transport of the dust by the middle-latitude westerlies. It will be discussed below (Section 4.2) through trajectory analyses.

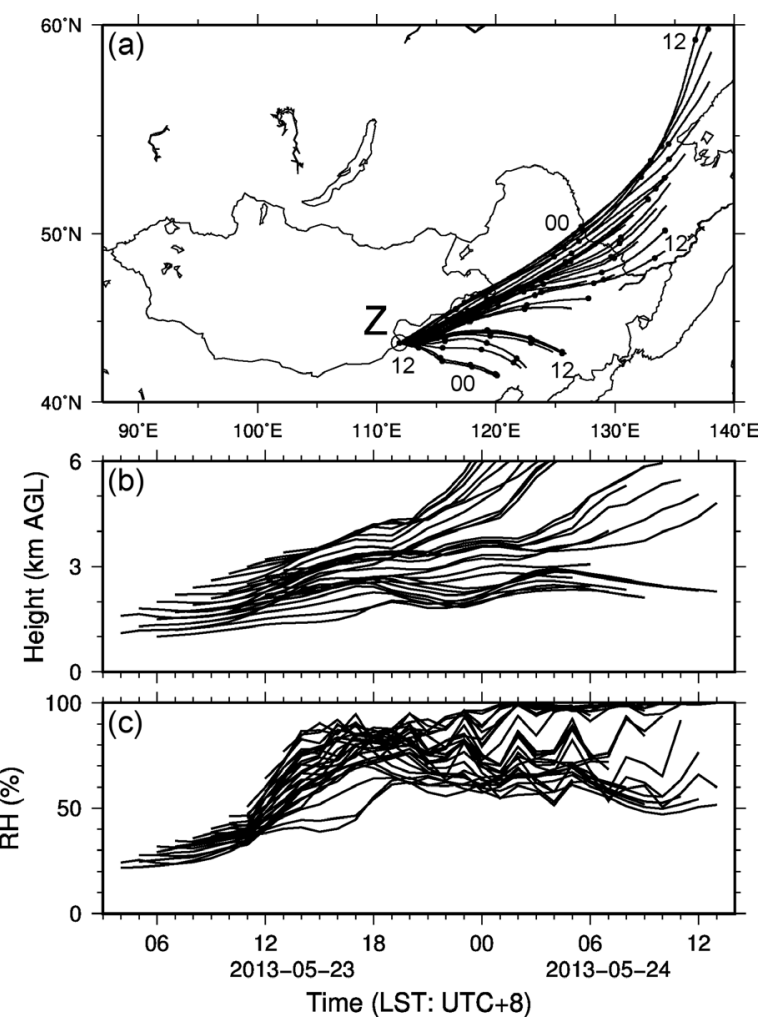

Fig. 16. Same as Fig. 14, except that the location is Zamyn-Uud, and the initial time of the forward trajectories is 23 May 2013.

\subsection{Long-range transport of the dust}

Forward trajectories for the dust layers observed in Sainshand and Zamyn-Uud are shown in Figs. 15 and 16 , respectively. The trajectories extended northeastward or eastward and reached northeastern China and the Russian Far East (Figs. 15a, 16a). These directions are consistent with the westerly winds over the cold air (Figs. 9a, 12a). Most of the trajectories extended upward and exceeded a height of $4 \mathrm{~km}$ (Figs. 15b, 16b). They were located in the free troposphere, where the middle-latitude westerlies prevail. The height increase of these trajectories agrees with the updrafts in the dust layers (Figs. 9b, 12b). Hence, it was caused by the updraft of warm air in the cold frontal system. The relative humidity along the trajectories increased and at times exceeded $80 \%$ (Figs. 15c, 16c). The high relative humidity indicates the presence of clouds. It is likely that the clouds were generated by the updraft of warm air in the cold frontal system. In conclusion, it is suggested that the dust produced during this dust event was transported over a long range by the west- 
erlies, as reported in previous studies (e.g., Kai et al. 1988; Husar et al. 2001; Hara et al. 2009; Uno et al. 2009; Yumimoto et al. 2009).

\section{Conclusions}

The Gobi Desert lidar network observed the spatial distributions of dust during the dust event that occurred over the desert on 22-23 May 2013. In this study, the dust event was analyzed by using the lidar network and various meteorological data. The main findings are summarized below.

(1) During the dust event, a cold front moved southeastward across the desert.

(2) In Dalanzadgad, in the central part of the desert, a dust storm was observed around the cold front from the ground to a height of $1.6 \mathrm{~km}$. A dust layer was distributed at a height of $0.9-1.6 \mathrm{~km}$ over the cold frontal surface. The updraft of warm air in the cold frontal system should have transported the dust emitted from the dust storm.

(3) In Sainshand and Zamyn-Uud, in the eastern part of the desert, a dust layer ascended from the ABL to the free troposphere over the cold air and reached a top height of about $4 \mathrm{~km}$. The dust layer was located in the updraft region of warm air.

(4) The overall dust layer was developing from the ABL up to the free troposphere while moving across the desert with the cold front. It is suggested that this development was caused by the combination of the continuous emission and transport of dust by the cold frontal system.

This is the first study showing the spatial development of a dust layer in association with a cold frontal system by using the Gobi Desert lidar network. It is important to maintain and expand the lidar network and analyze many dust events. This effort will help us better understand the mechanisms of the emission and transport of Asian dust.

\section{Acknowledgments}

The authors gratefully acknowledge the Dalanzadgad Meteorological Observatory for supporting the ceilometer observation, Dr. Atsushi Shimizu of NIES for teaching the calibration method of the AD-Net lidar data, JMA for the provision of weather charts (http://www.jma.go.jp/jma/), the National Climatic Data Center of NOAA for the provision of ISD data (https://www.ncdc.noaa.gov/isd), NCEP for the provision of FNL data (https://rda.ucar.edu/datasets/ ds083.2/), and the Air Resources Laboratory of NOAA for the provision of the HYSPLIT transport and dispersion model and the READY website (http://www. ready.noaa.gov). This study was supported by Grantsin-Aid for Scientific Research from JSPS (Nos. 24340111 and 16H02703) and by the JSPS Core-toCore Program (B. Asia-Africa Science Platforms).

\section{References}

Adachi, S., and F. Kimura, 2007: A 36-year climatology of surface cyclogenesis in East Asia using high-resolution reanalysis data. SOLA, 3, 113-116.

Adachi, S., F. Kimura, S. Sugata, M. Hayasaki, Y. Kurosaki, and S. Wakamatsu, 2007: Dust transport along a cold front: A case study of a cyclone observed on 19-20 April 2000 in Northeast Asia. J. Japan Soc. Atmos. Environ., 42, 327-338.

Chen, S.-J., Y.-H. Kuo, P.-Z. Zhang, and Q.-F. Bai, 1991: Synoptic climatology of cyclogenesis over East Asia, 1958-1987. Mon. Wea. Rev., 119, 1407-1418.

Hara, Y., K. Yumimoto, I. Uno, A. Shimizu, N. Sugimoto, Z. Liu, and D. M. Winker, 2009: Asian dust outflow in the PBL and free atmosphere retrieved by NASA CALIPSO and an assimilated dust transport model. Atmos. Chem. Phys., 9, 1227-1239.

Hayasaki, M., S. Sugata, and H. L. Tanaka, 2006: Interannual variation of cold frontal activity in spring in Mongolia. J. Meteor. Soc. Japan, 84, 463-475.

Huang, J., W. Zhang, J. Zuo, J. Bi, J. Shi, X. Wang, Z. Chang, Z. Huang, S. Yang, B. Zhang, G. Wang, G. Feng, J. Yuan, L. Zhang, H. Zuo, S. Wang, C. Fu, and J. Chou, 2008: An overview of the semi-arid climate and environment research observatory over the Loess Plateau. Adv. Atmos. Sci., 25, 906-921.

Huang, J., T. Wang, W. Wang, Z. Li, and H. Yan, 2014: Climate effects of dust aerosols over East Asian arid and semiarid regions. J. Geophys. Res., 119, 11398-11416.

Husar, R. B., D. M. Tratt, B. A. Schichtel, S. R. Falke, F. Li, D. Jaffe, S. Gassó, T. Gill, N. S. Laulainen, F. Lu, M. C. Reheis, Y. Chun, D. Westphal, B. N. Holben, C. Gueymard, I. McKendry, N. Kuring, G. C. Feldman, C. McClain, R. J. Frouin, J. Merrill, D. DuBois, F. Vignola, T. Murayama, S. Nickovic, W. E. Wilson, K. Sassen, N. Sugimoto, and W. C. Malm, 2001: Asian dust events of April 1998. J. Geophys. Res., 106, 18317-18330.

Jin, Y., K. Kai, K. Kawai, T. Nagai, T. Sakai, A. Yamazaki, A. Uchiyama, D. Batdorj, N. Sugimoto, and T. Nishizawa, 2015: Ceilometer calibration for retrieval of aerosol optical properties. J. Quant. Spectrosc. Radiat. Transfer, 153, 49-56.

Kai, K., Y. Okada, O. Uchino, I. Tabata, H. Nakamura, T. Takasugi, and Y. Nikaidou, 1988: Lidar observation and numerical simulation of a Kosa (Asian Dust) over Tsukuba, Japan during the Spring of 1986. J. Meteor. Soc. Japan, 66, 457-472.

Kai, K., Y. Nagata, N. Tsunematsu, T. Matsumura, H.-S. Kim, T. Matsumoto, S. Hu, H. Zhou, M. Abo, and T. Nagai, 2008: The structure of the dust layer over the Taklimakan Desert during the dust storm in April 2002 as observed using a depolarization lidar. $J$. Meteor. Soc. Japan, 86, 1-16.

Kawai, K., K. Kai, Y. Jin, N. Sugimoto, and D. Batdorj, 
2015: Dust event in the Gobi Desert on 22-23 May 2013: Transport of dust from the atmospheric boundary layer to the free troposphere by a cold front. SOLA, 11, 156-159.

Kurosaki, Y., and M. Mikami, 2005: Regional difference in the characteristic of dust event in East Asia: Relationship among dust outbreak, surface wind, and land surface condition. J. Meteor. Soc. Japan, 83A, 1-18.

Mikami, M., T. Aoki, M. Ishizuka, S. Yabuki, Y. Yamada, W. Gao, and F. Zeng, 2005: Observation of number concentration of desert aerosols in the south of the Taklimakan Desert, China. J. Meteor. Soc. Japan, 83A, 31-43.

Natsagdorj, L., D. Jugder, and Y. S. Chung, 2003: Analysis of dust storms observed in Mongolia during 19371999. Atmos. Environ., 37, 1401-1411.

Sakai, T., T. Nagai, M. Nakazato, Y. Mano, and T. Matsumura, 2003: Ice clouds and Asian dust studied with lidar measurements of particle extinction-to-backscatter ratio, particle depolarization, and water-vapor mixing ratio over Tsukuba. Appl. Opt., 42, 7103-7116.

Sassen, K., 2006: Polarization in lidar. Lidar: RangeResolved Optical Remote Sensing of the Atmosphere. Weitkamp, C. (ed.), Springer, USA, 19-42.

Shao, Y., and J. Wang, 2003: A climatology of Northeast Asian dust events. Meteor. Z., 12, 187-196.

Shimizu, A., N. Sugimoto, I. Matsui, K. Arao, I. Uno, T. Murayama, N. Kagawa, K. Aoki, A. Uchiyama, and A. Yamazaki, 2004: Continuous observations of Asian dust and other aerosols by polarization lidars in China and Japan during ACE-Asia. J. Geophys. Res., 109, D19S17, doi:10.1029/2002JD003253.

Simpson, J. E., 1997: Gravity Currents: In the Environment and the Laboratory. 2nd Edition. Cambridge University Press, $244 \mathrm{pp}$.

Smith, A., N. Lott, and R. Vose, 2011: The integrated surface database: Recent developments and partnerships. Bull. Amer. Meteor. Soc., 92, 704-708.

Stein, A. F., R. R. Draxler, G. D. Rolph, B. J. B. Stunder, M. D. Cohen, and F. Ngan, 2015: NOAA's HYSPLIT atmospheric transport and dispersion modeling system.
Bull. Amer. Meteor. Soc., 96, 2059-2077.

Sugimoto, N., I. Matsui, A. Shimizu, T. Nishizawa, Y. Hara, C. Xie, I. Uno, K. Yumimoto, Z. Wang, and S.-C. Yoon, 2008: Lidar network observations of tropospheric aerosols. Proc. SPIE, 7153, 71530A, doi:10.1117/ 12.806540 .

Sun, J., M. Zhang, and T. Liu, 2001: Spatial and temporal characteristics of dust storms in China and its surrounding regions, 1960-1999: Relations to source area and climate. J. Geophys. Res., 106, 10325-10333.

Takemi, T., 2005: Explicit simulations of convective-scale transport of mineral dust in severe convective weather. J. Meteor. Soc. Japan, 83A, 187-203.

Takemi, T., and N. Seino, 2005: Dust storms and cyclone tracks over the arid regions in east Asia in spring. J. Geophys. Res., 110, D18S11, doi:10.1029/2004JD 004698.

Tsunematsu, N., T. Sato, F. Kimura, K. Kai, Y. Kurosaki, T. Nagai, H. Zhou, and M. Mikami, 2005: Extensive dust outbreaks following the morning inversion breakup in the Taklimakan Desert. J. Geophys. Res., 110, D21207, doi:10.1029/2005JD005994.

Uno, I., K. Eguchi, K. Yumimoto, T. Takemura, A. Shimizu, M. Uematsu, Z. Liu, Z. Wang, Y. Hara, and N. Sugimoto, 2009: Asian dust transported one full circuit around the globe. Nat. Geosci., 2, 557-560.

Wallace, J. M., and P. V. Hobbs, 2006: Atmospheric Science: An Introductory Survey. 2nd Edition. Academic Press, 504 pp.

Wang, X., P. Zhai, and C. Wang, 2009: Variations in extratropical cyclone activity in northern East Asia. $A d v$. Atmos. Sci., 26, 471-479.

Wu, J., Y. Kurosaki, M. Shinoda, and K. Kai, 2016: Regional characteristics of recent dust occurrence and its controlling factors in East Asia. SOLA, 12, 187-191.

Yumimoto, K., K. Eguchi, I. Uno, T. Takemura, Z. Liu, A. Shimizu, and N. Sugimoto, 2009: An elevated largescale dust veil from the Taklimakan Desert: Intercontinental transport and three-dimensional structure as captured by CALIPSO and regional and global models. Atmos. Chem. Phys., 9, 8545-8558. 